\title{
ESTIMATES OF SOIL WATER CONTENT USING GROUND PENETRATING RADAR IN FIELD CONDITIONS
}

\author{
Marcelo Jorge Luz Mesquita ${ }^{1}$, José Gouvêa Luiz ${ }^{1}$ and José de Paulo Rocha da Costa ${ }^{2}$
}

\begin{abstract}
Electromagnetic methods play an important role in the study of soil water content, mainly because electromagnetic properties in the shallow subsurface area are primarily controlled by the presence of water. This work analyzes the effectiveness of Ground Penetrating Radar (GPR) as a tool for estimating soil water content in field conditions, introduces a calibration equation to estimate average soil moisture of the area studied from the analysis of GPR wave velocity, and evaluates the process used to create it. Methodologies for collecting GPR data seeking the determination of soil moisture from the velocity of the electromagnetic wave and the use of equations proposed in the literature, Topp and Roth, are also discussed. The GPR common-offset methodology (400 MHz antennas) was utilized in a study in Cuiarana, Salinópolis, Pará State, in northern Brazil and the resulting data compared with data from TDR (Time Domain Reflectometry) (0.12 m double probe) methodology. The data were then statistically analyzed enabling the establishment of a calibration equation for water content determination in terms of electromagnetic wave velocity obtained with GPR. The study successfully showed the feasibility and limitations of estimating water content using GPR. Also is discussed the possibility of calibration equation to the soil water content analysis with GPR data using, as parameter, data obtained by other indirect method, in this case, the TDR.
\end{abstract}

Keywords: soil water content, relative permittivity, GPR, TDR, wave velocity.

RESUMO. Os métodos eletromagnéticos são uma importante ferramenta no estudo da umidade do solo, principalmente porque as propriedades eletromagnéticas da subsuperfície rasa são controladas pela presença de água. Este trabalho, além de analisar a eficácia do Radar de Penetração no Solo (GPR) como ferramenta de medição da umidade do solo in situ sob condições de campo não controladas, introduz uma equação de calibração para estimar a umidade do solo da área estudada a partir da análise da velocidade da onda do GPR e avalia o processo da sua criação. São também discutidas as metodologias comumente empregadas na coleta de dados com o GPR, visando a determinação da umidade do solo a partir da velocidade da onda eletromagnética, assim como a utilização das equações propostas na literatura, Topp e Roth. A metodologia common-offset (GPR com antenas de $400 \mathrm{MHz}$ ) foi empregada em um estudo realizado em Cuiarana, município de Salinópolis, Pará, no norte do Brasil e os dados comparados com medidas de umidade realizadas com TDR (sonda dupla de $0,12 \mathrm{~m}$ ). Os dados foram estatisticamente correlacionados permitindo 0 estabelecimento de uma equação de calibração para a determinação de umidade em termos da velocidade da onda eletromagnética obtida com 0 GPR. 0 estudo demonstrou com sucesso a viabilidade, a rapidez e as limitações do GPR na estimativa do conteúdo de água no solo. Também é discutida a possibilidade da calibração de equação para análise de umidade com o GPR usando como parâmetro dados obtidos por outro método indireto, neste caso, o TDR.

Palavras-chave: umidade do solo, permissividade relativa, GPR, TDR, velocidade da onda.

\footnotetext{
${ }^{1}$ Universidade Federal do Pará, Programa de Pós-Graduação em Geofísica, Rua Augusto Correa, 1, 66075-110 Belém, PA, Brazil. Phone: +55(91) 3201-7692; Fax: +55(91) 3201-7693 - E-mails: marjlm@hotmail.com; gouvea@ufpa.br

2Universidade Federal do Pará, Faculdade de Meteorologia, Rua Augusto Correa, 1, 66075-110 Belém, PA, Brazil. Phone: +55(91) 3201-7671; Fax: +55(91) 3201-7475 - E-mail: jpaulo@ufpa.br
} 


\section{INTRODUCTION}

The vadose zone (VZ) has been defined as the transition zone between the atmosphere and underground water reservoirs. VZ plays a fundamental role in managing water resources. These essential roles include: (1) VZ regulates the availability of water for all types of vegetation and crops; (2) VZ simultaneously creates a protective layer against solutes and pollutants (Rubin, 2003); (3) In continental regions, VZ regulates the exchange of moisture and energy between soil, vegetation and the atmosphere; (4) Consequently, VZ affects other parameters such as atmospheric humidity and temperature which ultimately define the local climate (Huisman et al., 2003).

Information about the spatial distribution of soil water content is of utmost importance to precision farming programs. Even with a plentiful water supply, crop quality can still decline due to adverse effects on VZ such as reduced root transpiration related to the depletion of $\mathrm{O}_{2}$ and increased toxic ions in the soil from root plant flooding. With little water, crops are normally damaged irreversibly due to stress. Furthermore, energy and irrigation costs are quite high in regions where water is scarce, especially in places where there is additional competition for limited water resources (Huisman et al., 2003).

Electromagnetic methods play an important role in this type of VZ study because electromagnetic properties in the shallow surface area are primarily controlled by the presence of water (Topp et al., 1980) due to the high value of waters relative electrical permittivity when compared with most geological materials which have a lower relative permittivity range.

Five conventional small-scale methods for estimating soil water content include:

(1) gravimetric (drying and weighing in the laboratory);

(2) TDR (Time Domain Reflectometry);

(3) FDR (Frequency Domain Reflectometry);

(4) neutron probe; and

(5) capacitance probe.

Two weaknesses of these common methods include their invasive nature and limited spatial coverage (Lunt et al., 2005).

One of the most successful methods is TDR which was first used for soil studies in the mid-1980s (Topp et al., 1980) and has become widely used to estimate soil water content. However, TDR can be ineffective when measuring small volumes of water in soil (less than $\mathrm{dm}^{3}$ ) due to its extreme sensitivity to macropores and air bubbles caused by the introduction of the probes (Huisman et al., 2003). On the other hand, although the initial focus of GPR (Ground Penetrating Radar) was to map subsurface structures, its use to estimate soil water content has increased in recent years. Extensive research on the subject has been performed worldwide. For example, to determine if GPR can be used as a soil water content sensor in sandy soils in situ, Weiler et al. (1998) proposed and successfully determined that the calibration equation for TDR is also valid for GPR.

Steelman \& Endres (2011) examined the ability of various empirical relationships, based on volumetric mixing formulas and effective medium approximations, and then predicted nearsurface volumetric soil water content by using high frequency direct ground wave velocity measurements for three soil texture samples. Steelmean \& Endres (2011) compared those results to the ones obtained from the gravimetric method.

Lunt et al. (2005) showed that reflections in common-offset GPR, with a $100 \mathrm{MHz}$ antenna, can be used to estimate soil water content levels under various conditions of moisture saturation with an RMS error of $0.018 \mathrm{~m}^{3} \mathrm{~m}^{-3}$, besides being compared to the other main methods: neutron probe, TDR, and the capacitance probe. Common-offset GPR offers the advantage of speed when investigating large areas.

Grote et al. (2010) used the GPR to characterize the spatial correlation of water content in a three acre field as a function of sampling depth, season, vegetation, and soil texture. The GPR data was acquired with 450 and $900 \mathrm{MHz}$ antennas. Measurements of GPR groundwave were used to estimate soil water content at four different times. Additional water content estimates were obtained using both time domain reflectometry measurements and soil texture measurements. These measurements demonstrated that precipitation and irrigation increase the spatial variability of water content while shallowly-rooted vegetation decreases spatial variability. The study showed that soil texture generally has a greater small-scale spatial correlation than water content and that the variability of water content in deeper soil layers was more closely correlated to soil texture than shallower water content measurements.

In this paper, the efficiency of common-offset GPR configuration is analyzed as an in situ rapid soil water content meter based on uncontrolled field conditions on a survey done at the Meteorology Department test site of the Institute of Geosciences, Universidade Federal do Pará (UFPA). The GPR water content data were compared to TDR water content data obtained during the survey, with TDR calibrated for the area. We used the well-known Topp and Roth equations for testing and estimating moisture from the GPR data. We also established a new calibration equation from 
the analysis of diffraction hyperbolas detected in radar profiles and moisture obtained in the TDR measurements. For this calibration equation we used the three-phase model.

\section{THEORY}

\section{Principles of GPR}

The GPR method consists in radiating electromagnetic waves with frequencies ranging from 10 to $2500 \mathrm{MHz}$ via a transmitting antenna placed near the surface. As these waves pass through the soil, they are reflected, refracted, and diffracted by electromagnetic heterogeneities they encounter. The reflected waves that return to the surface are detected by the same transmitting antenna or another antenna placed nearby.

In the case of homogeneous soils, the velocity of propagation of the GPR wave $(v)$ is basically controlled by the relative permittivity $\left(\epsilon_{r}\right)$, that is, the permittivity relative to free space as calculated by the absolute permittivity, $\epsilon\left(\mathrm{F} \mathrm{m}^{-1}\right)$, divided by the free space permittivity $\epsilon_{0}\left(\mathrm{~F} \mathrm{~m}^{-1}\right)$, and can be estimated in nonmagnetic media by:

$$
v=\frac{c}{\sqrt{\epsilon_{r}}},
$$

where $c$ represents the speed of light.

Values of $\epsilon_{r}$ are used for moisture determination. To obtain $v$ and calculate $\epsilon_{r}$ from Eq. (1) for the soil moisture estimate, measurements of underground reflected waves and surface reflected waves can be utilized, along with measurements in boreholes (transillumination or radar tomography) and surface reflections. Figure 1 presents a schematic diagram showing the GPR antennas and propagation paths. All these waves can be used to measure soil water content (Huisman et al., 2003).

\section{Using reflected waves}

Two methods for determining $v$ and $\epsilon_{r}$ from the arrival time of reflected waves can be employed. The first method involves transmitting and receiving antennas positioned at the same distance while moving along the profile and is referred as the commonoffset method. The second method utilizes transmitting and receiving antennas positioned at varying distances while moving along the profile and is known as the multi-offset method. Both methods are discussed below.

a) Common-offset - The transmitter and receiver antennas are separated at a constant distance while being moved along the predetermined profile. Hyperbolic patterns are searched in the GPR image for wave velocity determination. The average velocity between the ground surface and the anomaly $\left(v_{\text {soil }}\right)$ can be determined by a GPR transect by fitting the following hyperbola to measure arrival times at several positions $x$. This velocity is given by:

$$
v_{\text {soil }}=\frac{2 \sqrt{x^{2}+d^{2}}}{t_{r w, x}},
$$

where $x$ is the position relative to the position of the scattering object (apex of the hyperbola), $d$ is the depth of scattering object, and $t_{r w, x}$ is the arrival time of the reflected wave at position $x$ that has been zero time corrected (Huisman et al., 2003).

If the GPR section is measured with significant antenna separation, $a$, this should also be included in the velocity determination as follows:

$v_{\text {soil }}=\frac{\sqrt{(x-0.5 a)^{2}+d^{2}}+\sqrt{(x+0.5 a)^{2}+d^{2}}}{t_{r w, x}}$.

Data processing softwares provide routines whereby the velocity can be determined interactively by the manual fitting of the hyperbolic pattern.

b) Multi-offset - Two acquisition geometries are often used in the multi-offset method: CMP (Common Mid-point) and WARR (Wide Angle Reflection and Refraction). In CMP, the distance between the antennas is increased symmetrically to a fixed point. In WARR methodology, only the receiver antenna is moved while the transmitter antenna remains fixed.

If consistent reflected waves are present in the multi-offset GPR measurement, they can be used to calculate soil water content directly by fitting

$$
v_{\text {soil }}=\frac{2 \sqrt{d^{2}+(0.5 a)^{2}}}{t_{r w, a}},
$$

to the zero time corrected arrival times of the reflected wave $\left(t_{r w, a}\right)$ for different antenna separations, and solving for depth, and the average velocity to the reflecting layer.

\section{Using surface waves}

Velocity is obtained from surface waves by using the multi-offset configurations, either CMP or WARR geometry.

\section{Using boreholes}

This technique consists of placing the transmitting antenna and the receiving antenna in laterally adjacent boreholes. In the zero offset-profile mode (ZOP), the antennas are located so that their midpoints are always at the same depth. Based on this ZOP model, the arrival time of the direct wave and the distance between the boreholes are used to calculate wave velocity. The water content between the boreholes can also be determined from multi-offset profiling (MOP) through the construction of 


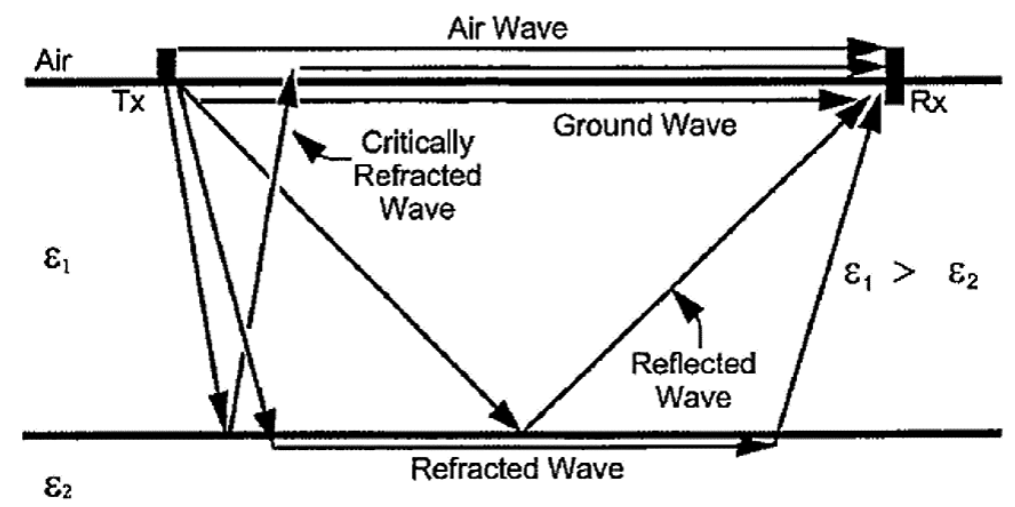

Figure 1 - Propagation paths of electromagnetic waves in a soil with two layers of contrasting dielectric permittivity $\left(\epsilon_{1}\right.$ and $\left.\epsilon_{2}\right)$ (Huisman et al., 2003).

a 2D image. The first arrival times of all multi-offset measurements are used to reconstruct a two-dimensional tomographic image of the soil water content distribution between the boreholes (Hubbard et al., 1997; Huisman et al., 2003).

\section{Using surface reflections}

In this case, the antennas are operated at some distance above the surface. The measured property is the reflection coefficient of the surface-air interface. The measurements are more practicable with frequency antennas greater than $200 \mathrm{MHz}$, because the reflection coefficient is more sensitive to low water content (Huisman et al., 2003). The application of this methodology in rough surfaces and in places with variations in soil water content based on depth leads to an underestimation of soil water content because soil irregularities cause significant scattering in the waves, thereby decreasing the reflection coefficient (Huisman et al., 2003).

\section{Principles of TDR}

TDR is a technology originally used by the telecommunication and electricity industries to find possible faults in cables. In simplified terms, TDR is composed of an electrical pulse generator and an oscilloscope. TDR measures the velocity of electromagnetic waves as they travel through a transmission line. In summary, physical principles of TDR are similar to GPR. Both emit electromagnetic waves, but each one measures the relative permittivity in a slightly different form. TDR technology measures wave velocity as it travels along and between probes, while GPR methodology measures waves that travel directly through the soil and reflected at interfaces with different dielectric permittivities (Weiler et al., 1998).
The TDR sensor is composed of two or more metallic parallel probes. The probes are connected via coaxial cable to the equipment that sends a signal to the probes. When the signal reaches the beginning of the probes, it is reflected back to the measuring device. When the signal reaches the end of the probes, a second reflection returns to the transmitting device (Siddiqui \& Drnevich, 1995).

The velocity of the wave traveling through the soil for the TDR is calculated via:

$$
v=\frac{2 L}{t},
$$

where $t$ represents the two-way traveltime for the signal to travel distance $L$, which represents the length of the probes. The relative permittivity of the soil is then calculated by:

$$
\epsilon_{r}=\left(\frac{c}{v}\right)^{2}=\left(\frac{c t}{2 L}\right)^{2}
$$

At least four precautions are necessary to assure valid measurements regarding the positioning of the probes in the ground: (1) the probe is more sensitive to permittivity close to the rods. So probes inserted in a manner which generates air voids around the rods will have reduced measurement accuracy (Campbell Scientific, 2011); (2) the probes must remain parallel; (3) to ensure parallel probes, it is suggested to use a fixing base; and (4) avoid measurements in areas with rocks and materials that may bend the unit.

Currently, many equipment comes calibrated to estimate moisture for a wide variety of soils. In some cases, it is necessary to perform calibration for a particular type of soil, such as soil with a high density, magnetic and very saline. This ensures a better estimate and decreases the percentage of errors. 


\section{Equations for GPR water content estimation}

Most equations are derived from experiments based on TDR measurements. Various researchers (Weiler et al., 1998; Huisman et al., 2001) have shown that calibration equations based on TDR measurement have been applied very successfully in large-scale studies based on GPR measurements (Lunt et al., 2005).

This study is based on the following three equations accompanied by further explanation: (a) Topp Equation; (b) Roth Equation; and (c) Three-Phase Model Equation.

(a) Topp equation - It is an empirical relationship between relative permittivity $\epsilon_{r}$ and volumetric water content $\theta \mathrm{m}^{3} \mathrm{~m}^{-3}$. It was proposed by Topp et al. (1980) using experimental laboratory data based on different soil textures. The Topp Equation is expressed by:

$$
\begin{gathered}
\theta_{T O P P}\left(\epsilon_{r}\right)=-5.3 \times 10^{-2}+2.92 \times 10^{-2} \epsilon_{r} \\
-5.5 \times 10^{-4} \epsilon_{r}^{2}+4.3 \times 10^{-6} \epsilon_{r}^{3} .
\end{gathered}
$$

This equation describes soil water content based on the values $\theta_{T O P P}<0.5 \mathrm{~m}^{3} \mathrm{~m}^{-3}$ with an estimated error margin of $0.013 \mathrm{~m}^{3} \mathrm{~m}^{-3}$ and accurate to within $0.022 \mathrm{~m}^{3} \mathrm{~m}^{-3}$. The Topp Equation does not depend on density, temperature, or soil salinity. However, it is not suitable for organic soils (or mineral soils with high organic content) and vermiculite (Topp et al., 1980).

(b) Roth equation - This equation was determined by Roth et al. (1992) in a study to infer the relationship between $\theta$ and $\epsilon_{r}$ by using samples of eleven different mineral soils and seven organic soils, each one with distinct chemical, physical, and magnetic properties. This study enabled Roth et al. (1992) to formulate the following calibration equation:

$$
\begin{gathered}
\theta_{\text {ROTH }}\left(\epsilon_{r}\right)=-7.8 \times 10^{-2}+4.48 \times 10^{-2} \epsilon_{r} \\
-1.95 \times 10^{-3} \epsilon_{r}^{2}+3.61 \times 10^{-5} \epsilon_{r}^{3} .
\end{gathered}
$$

(c) Three-phase model equation - This semi-empirical equation that relates $\theta$ and $\epsilon_{r}$ is based on models of mixed permittivities, taking in account the volume and dielectric permittivity of three constituents: soil, water, and air (e.g., Dobson et al., 1985; Roth et al., 1990). In this model, the permittivity of the bulk soil, including soil-water-air $\left(\epsilon_{b}\right)$ is expressed as the Complex Refractive Index Model (CRIM):

$$
\epsilon_{b}=\left[\theta_{w}^{\alpha}+(1-n) \epsilon_{s}^{\alpha}+(n-\theta) \epsilon_{a}^{\alpha}\right]^{\frac{1}{\alpha}},
$$

where $n\left(\mathrm{~m}^{3} \mathrm{~m}^{-3}\right)$ represents the porosity of the medium; $\epsilon_{w}, \epsilon_{s}$ and $\epsilon_{a}$ represent the relative permittivity of water, soil, and air, respectively. $\alpha$ represents the orientation factor related to the electric field over the geometry of the medium ( $\alpha=1$ for the electric field parallel in soil layers, $\alpha=-1$ for an electric field perpendicular to the layers of soil, and $\alpha=0.5$ for an isotropic medium). Rearranging Eq. (9) to obtain moisture leads to:

$$
\theta=\frac{\epsilon_{b}^{\alpha}-(1-n) \epsilon_{s}^{\alpha}-n \epsilon_{a}^{\alpha}}{\epsilon_{w}^{\alpha}-\epsilon_{a}^{\alpha}} .
$$

Substituting the values 1 for $\epsilon_{a}$ and 0.5 for $\alpha$, results in the simple physical interpretation relating electrical permittivity and soil water content, as suggested by Ledieu et al. (1986) and Herkelrath et al. (1991):

$$
\theta_{T P M}\left(\epsilon_{b}\right)=a \sqrt{\epsilon_{b}}-b,
$$

where

$$
a=\frac{1}{\sqrt{\epsilon_{w}}-1}
$$

and

$$
b=\frac{(1-n) \sqrt{\epsilon_{s}}+n}{\sqrt{\epsilon_{w}}-1},
$$

are designated as calibration parameters; while $\epsilon_{b}$ can be considered as the relative permittivity of the medium.

\section{MATERIAL AND METHODS}

The study was conducted at a test site of the Institute of Geosciences of UFPA located in Cuiarana, a fishing village in the city of Salinópolis in northeast Pará, in northern Brazil. The site is characterized by the presence of bush vegetation and stunted trees. Due to the presence of a $1 \mathrm{~m}$ deep trench made on site to study depth moisture via TDR, it was possible to visualize the geological characteristics of the shallow site. These characteristics included a homogeneous medium (we considered up to $0.5 \mathrm{~m}$ deep) with the presence of Yellow Latosol, very common in this region (Torres, 2011).

\section{GPR data acquisition}

Profiles were acquired with a GSSI model SIR-3000 using the common-offset configuration with $400 \mathrm{MHz}$ antennas and a recording time window of 50 ns. Considering the site materials, we estimate in 2 meters the penetration depth. Details of the profiles are described below:

Profile 1 - Extension of $12 \mathrm{~m}$ (Figs. 2 and $3 \mathrm{~A}$ ) and direction N80E. This profile is approximately $0.3 \mathrm{~m}$ west of a trench (I0cated at the $8 \mathrm{~m}$ position).

Profile 2 - Extension of $10 \mathrm{~m}$, perpendicular to profile 1 and under a tree at the $6 \mathrm{~m}$ position (Figs. 2 and 3B). 


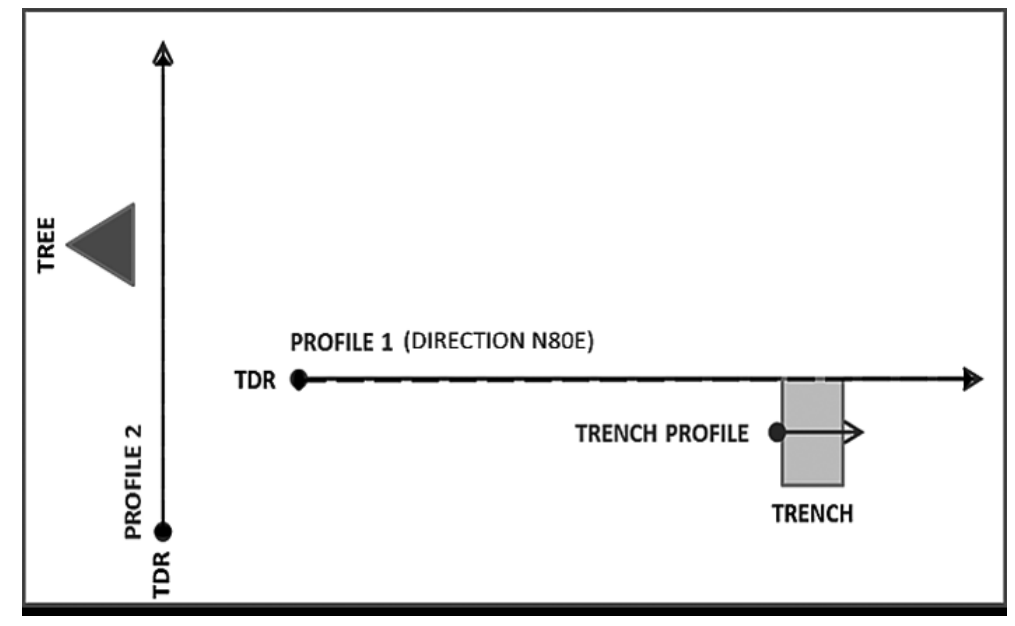

Figure 2 - Schematic (no scale) representation of the profiles in the study area.

Trench profile - Profile executed near profile 1 and on the top of the trench (Fig. 2). This trench (1 $\mathrm{m}$ deep) was created to carry out measurements of water content at depth. It was dug and then the TDR sensors are placed (0.2, 0.5 and $1.0 \mathrm{~m}$ deep) so that measurements could be done along a period of time. After being filled, the profile of GPR was conducted.

\section{Data acquisition with TDR}

The measurements were performed with a Hydrosense Soil Water Measurement System (CS655L) from Campbell Scientific, Inc, with a display unit and two parallel sensor probes of $0.12 \mathrm{~m}$ (Figs. 4A and 4B) calibrated for the area. The calibration coefficients used to transform the probe output signal to water content or deficit reside in the Hydro Sense operating system and were determined in laboratory studies on typical soils (Campbell Scientific, 2011). This system determines the total volume of $3600 \mathrm{~cm}^{3}$ (approximately $7.5 \mathrm{~cm}$ radius around each probe rod and $4.5 \mathrm{~cm}$ beyond the end of the rods). The volume water content range from 5 to $50 \%$ (Campbell Scientific, 2012).

\section{RESULTS}

GPR data were processed using the software ReflexW (Sandmeier, 2011). The wave velocities were determined through hyperbole fitting. The hyperboles of diffraction were identified in the radargrams and then obtained wave velocities in "packages" located above the diffraction points. These points are related, probably, to roots of the trees on site, old and buried roots and gravel. The values of relative permittivity of the medium were determined through Eq. (1) and the soil moisture values through Topp and Roth equations. The results for each profile are explained below.
Profile 1 - Figure 5a presents GPR profile 1 without hyperbolae fitting. Figure $5 b$ shows TDR soil water content values for each point of the GPR image illustrated in Figure $5 c$. The TDR data (values in black) were collected every $2 \mathrm{~m}$ in the profile (Fig. 5b). Due to the presence of many diffraction hyperbolas between each pair of points, the values for soil water content were determined by the average of adjacent values (values in red). A large anomaly caused by the trench is observed at the position $8 \mathrm{~m}$ and depth $0.8 \mathrm{~m}$. Values of GPR wave velocity, hyperbole depths, relative permittivity, water content values with TDR, and soil water content values obtained using Topp and Roth equations estimated from GPR wave velocity are shown in Table 1.

Profile 2 - Figure 6a presents GPR profile 2 without hyperbolae fitting. Figure $6 b$ shows soil water content values obtained with TDR, while Figure $6 c$ shows the GPR image with hyperbola fitting. Several GPR responses were likely caused by the presence of the roots of a tree at $6 \mathrm{~m}$. Table 2 is similar to Table 1 .

Trench profile - For this profile (Fig. 7), we considered soil water content values measured by TDR in the trench located from 6 to $10 \mathrm{~m}$. Table 3 shows the soil moisture values on the day of the study from 11:00 AM to 11:00 PM using TDR at three depths: $0.2,0.5$ and $1.0 \mathrm{~m}$. Soil water content values decreased slightly during the day at depths of 0.2 and $0.5 \mathrm{~m}$ and their daily average stayed on 0.2464 and $0.2103 \mathrm{~m}^{3} \mathrm{~m}^{-3}$, respectively. The soil water content measured at $1 \mathrm{~m}$ stayed on $0.1914 \mathrm{~m}^{3} \mathrm{~m}^{-3}$ without a substantial variation. The hyperbole detached in Figure 7 at $0.3 \mathrm{~m}$ depth was compared with the TDR measurements. The adjusted velocity at the $0.3 \mathrm{~m}$ depth hyperbole results in $\epsilon_{r}=14.06, \theta_{T O P P}=0.2608 \mathrm{~m}^{3} \mathrm{~m}^{-3}$ and $\theta_{\text {ROTH }}=$ $0.2668 \mathrm{~m}^{3} \mathrm{~m}^{-3}$. 


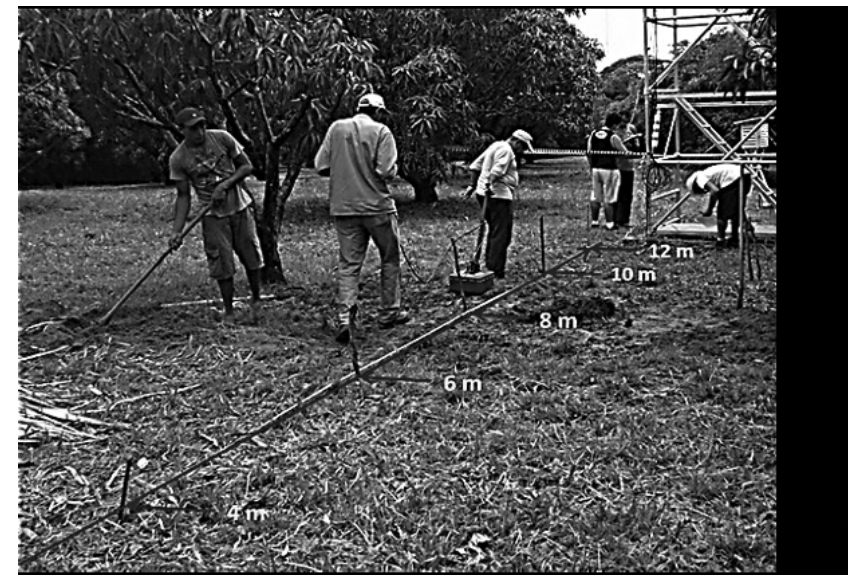

(A)

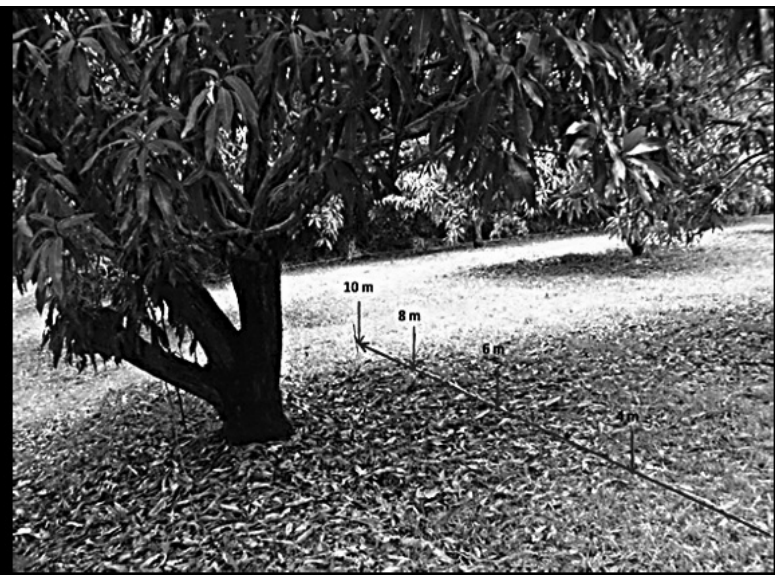

(B)

Figure 3 - Photos showing the GPR profiles. A) Profile 1. B) Profile 2.

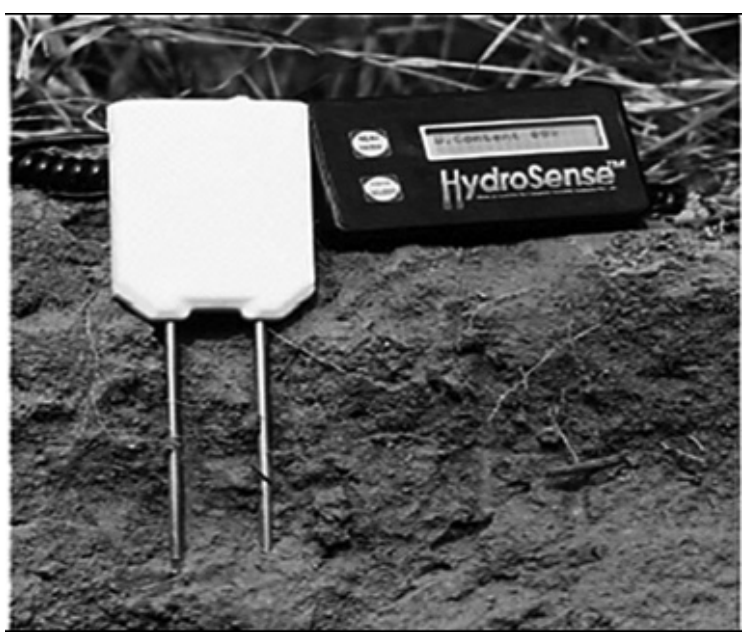

(A)

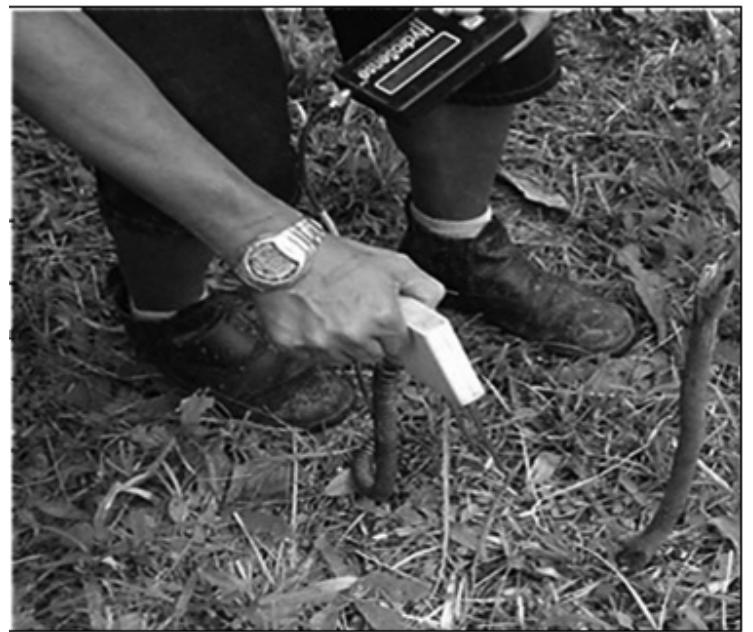

(B)

Figure 4 - A) TDR Hydrosense Soil Water Measurement System (Campbell Scientific, 2011). B) Collecting data using TDR Hydrosense Soil Water Measurement System.

Table 1 - Soil water content obtained from GPR velocity and TDR in profile 1.

\begin{tabular}{|c|c|c|c|c|c|c|}
\hline $\begin{array}{c}\text { GPR velocity } \\
(\mathrm{m} / \mathrm{ns})\end{array}$ & $\begin{array}{c}\text { Hyperbole depth } \\
(\mathrm{m})\end{array}$ & $\epsilon_{r}$ & $\begin{array}{c}\theta_{T D R} \\
\left(\mathrm{~m}^{3} \mathrm{~m}^{-3}\right)\end{array}$ & $\begin{array}{c}\theta_{T O P P} \\
\left(\mathrm{~m}^{3} \mathrm{~m}^{-3}\right)\end{array}$ & $\begin{array}{c}\theta_{R O T H} \\
\left(\mathrm{~m}^{3} \mathrm{~m}^{-3}\right)\end{array}$ & $\begin{array}{c}\text { Standard deviation } \\
\left(\mathrm{m}^{3} \mathrm{~m}^{-3}\right)\end{array}$ \\
\hline 0.090 & 0.5 & 11.11 & 0.225 & 0.2094 & 0.2286 & 0.0102 \\
0.080 & 0.3 & 14.06 & 0.300 & 0.2608 & 0.2668 & 0.0211 \\
0.080 & 0.3 & 14.06 & 0.250 & 0.2608 & 0.2668 & 0.0085 \\
0.078 & 0.2 & 14.79 & 0.250 & 0.2725 & 0.2749 & 0.0137 \\
0.075 & 0.4 & 16.00 & 0.290 & 0.2910 & 0.2875 & 0.0018 \\
0.070 & 0.4 & 18.37 & 0.265 & 0.3244 & 0.3107 & 0.0311 \\
0.067 & 0.5 & 20.05 & 0.260 & 0.3460 & 0.3273 & 0.0452 \\
\hline
\end{tabular}




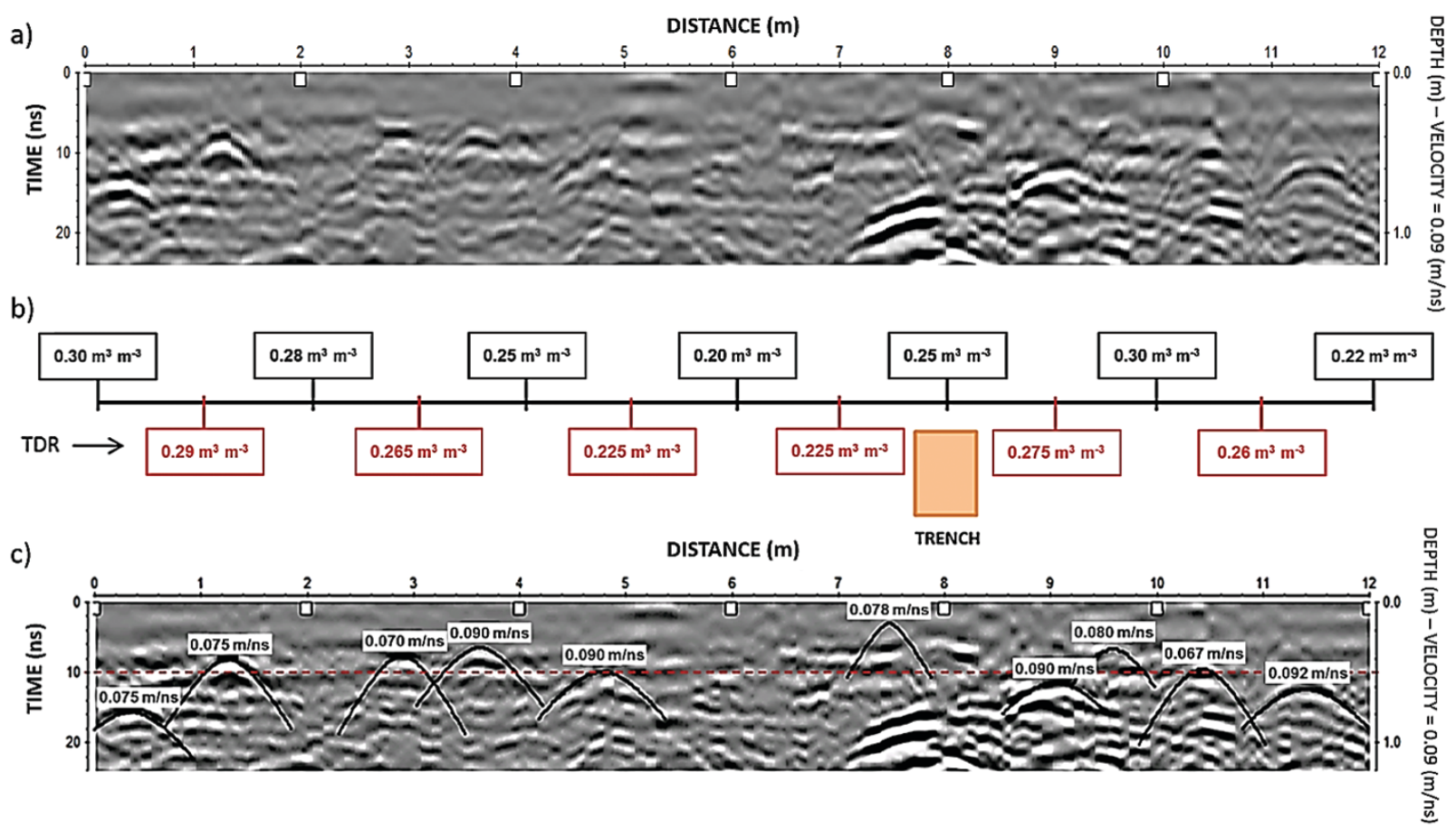

Figure 5-a) GPR profile 1 without hyperbolae fitting. b) Water content values obtained using TDR in profile 1 (values in black). Values in red represent the arithmetic mean of the adjacent values measured by TDR (in black). c) GPR image for profile 1 showing the hyperboles used in velocity determination. The dashed line represents the depth limit at which the reflection hyperbolas were considered.

Table 2 - Soil water content obtained from GPR velocity and TDR in profile 2.

\begin{tabular}{|c|c|c|c|c|c|c|}
\hline $\begin{array}{c}\text { GPR velocity } \\
(\mathrm{m} / \mathrm{ns})\end{array}$ & $\begin{array}{c}\text { Hyperbole depth } \\
(\mathrm{m})\end{array}$ & $\epsilon_{r}$ & $\begin{array}{c}\theta_{T D R} \\
\left(\mathrm{~m}^{3} \mathrm{~m}^{-3}\right)\end{array}$ & $\begin{array}{c}\theta_{T O P P} \\
\left(\mathrm{~m}^{3} \mathrm{~m}^{-3}\right)\end{array}$ & $\begin{array}{c}\theta_{R O T H} \\
\left(\mathrm{~m}^{3} \mathrm{~m}^{-3}\right)\end{array}$ & $\begin{array}{c}\text { Standard deviation } \\
\left(\mathrm{m}^{3} \mathrm{~m}^{-3}\right)\end{array}$ \\
\hline 0.110 & 0.4 & 7.440 & 0.250 & 0.1355 & 0.1622 & 0.0599 \\
0.080 & 0.3 & 14.06 & 0.240 & 0.2608 & 0.2668 & 0.0141 \\
0.080 & 0.3 & 14.06 & 0.290 & 0.2608 & 0.2668 & 0.0154 \\
0.080 & 0.5 & 14.06 & 0.295 & 0.2608 & 0.2668 & 0.0183 \\
0.075 & 0.5 & 16.00 & 0.305 & 0.2910 & 0.2875 & 0.0093 \\
0.070 & 0.3 & 18.37 & 0.295 & 0.3244 & 0.3107 & 0.0147 \\
0.060 & 0.5 & 25.00 & 0.320 & 0.4004 & 0.3873 & 0.0431 \\
\hline
\end{tabular}

\section{Proposal of a calibration equation}

Topp and Roth equations are valid for a wide variety of soils. As "general" equations, they offer accurate results for a large amount of applications. However, to achieve more accurate results, a specific calibration equation for the soil type studied is sometimes necessary (e.g. Siddiqui \& Drnevich, 1995).

As illustrated in Tables 1 and 2, some water content values obtained from GPR velocity are different from TDR water content values. For these cases, we posted in Table 4 the arithmetic mean of $\theta_{T D R}$ for each velocity. In general the equations of Topp and Roth used to estimate soil water content showed accurate results and, on the average, values based on the Roth equation showed more accurate results.

We used the results shown in Table 4 to create a calibration equation using the method of least squares by fitting a curve relating the relative permittivity of the medium obtained through GPR and TDR volumetric water content. For this procedure, the simplified three-phase model equation (Eq. 11) was utilized, resulting in the calibration parameters adjusted empirically by linear regression. Whereas the results of water content obtained with TDR was consistent in that area, the calibration equation for the GPR was based on its findings. It is common to use direct 


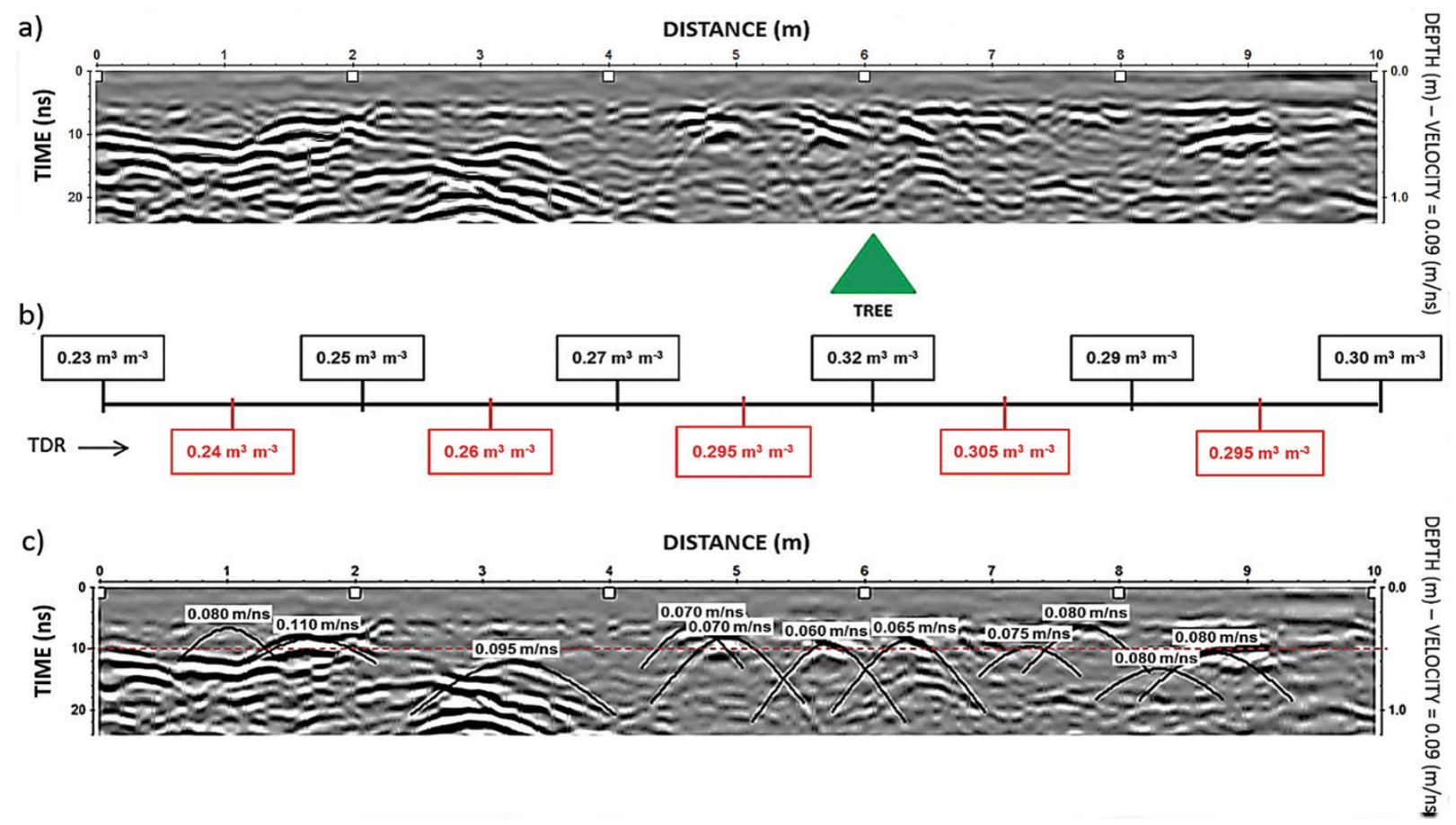

Figure 6 -a) GPR profile 2 without hyperbolae fitting. b) TDR water content measurements obtained in profile 2 (values in black). Values in red represent the arithmetic mean of the values measured by TDR (in black). c) GPR image for profile 2 showing the hyperboles used in velocity determination. The dashed line represents the depth limit at which the reflection hyperbolas were considered.

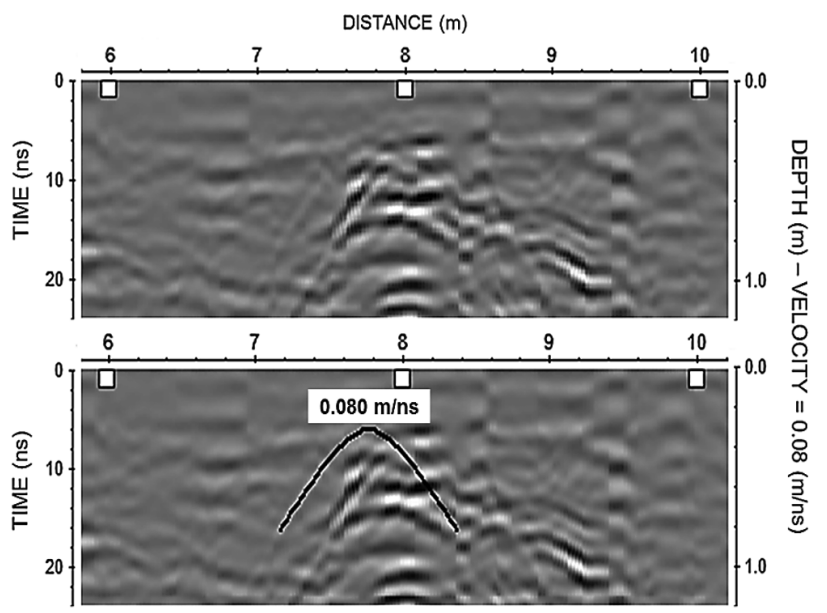

Figure 7 - Profile over the trench. The reflection hyperbole used to estimate the velocity is detached.

methods (gravimetric, for example) to be used as parameters for creating calibration equations, in this case, for testing, it is suggested the use of TDR data, since they are consistent values of soil water content.

The calibration equation relating the permittivity is then given by:

$$
\theta_{C E}\left(\epsilon_{r}\right)=0.0308 \sqrt{\epsilon_{r}}+0.1488
$$

which can also be expressed in terms of the velocity of the GPR wave by:

$$
\theta_{C E}(v)=\frac{9.24 \times 10^{-3}}{v}+0.1488 .
$$

Figure 8 shows the GPR site-specific calibration curve (Eq. 14) fitted to the measured TDR soil water content, while in Figure 9 is shown a comparison between values obtained with TDR, 
Table 3 - Soil water content values obtained on the day of the study, using TDR in three depths: 0.2 , 0.5 and $1 \mathrm{~m}$. The last row shows the average soil moisture for the period from 11:00 AM to 11:00 PM.

\begin{tabular}{|c|c|c|c|}
\hline Hour & $\begin{array}{c}\theta_{T D R}\left(\mathrm{~m}^{3} \mathrm{~m}^{-3}\right) \\
\text { depth } 0.2 \mathrm{~m}\end{array}$ & $\begin{array}{c}\theta_{T D R}\left(\mathrm{~m}^{3} \mathrm{~m}^{-3}\right) \\
\text { depth } 0.5 \mathrm{~m}\end{array}$ & $\begin{array}{c}\theta_{T D R}\left(\mathrm{~m}^{3} \mathrm{~m}^{-3}\right) \\
\text { depth } 1 \mathrm{~m}\end{array}$ \\
\hline $11: 00$ & 0.243 & 0.211 & 0.192 \\
$13: 00$ & 0.241 & 0.211 & 0.191 \\
$15: 00$ & 0.239 & 0.211 & 0.192 \\
$17: 00$ & 0.238 & 0.210 & 0.191 \\
$19: 00$ & 0.237 & 0.210 & 0.191 \\
21:00 & 0.237 & 0.210 & 0.191 \\
23:00 & 0.236 & 0.209 & 0.192 \\
Arithmetic & 0.2464 & 0.2103 & 0.1914 \\
mean & & & \\
\hline
\end{tabular}

Table 4 - Results obtained after analysis of GPR profiles 1 and 2 to create a calibration equation relating relative permittivity and water content.

\begin{tabular}{|c|c|c|}
\hline $\begin{array}{c}\text { GPR velocity } \\
(\mathrm{m} / \mathrm{ns})\end{array}$ & $\epsilon_{r}$ & $\begin{array}{c}\theta_{T D R}\left(\mathrm{~m}^{3} \mathrm{~m}^{-3}\right) \\
\text { (arithmetic mean) }\end{array}$ \\
\hline 0.110 & 7.440 & 0.2500 \\
0.090 & 11.11 & 0.2250 \\
0.080 & 14.06 & 0.2750 \\
0.078 & 14.79 & 0.2500 \\
0.075 & 16.00 & 0.2975 \\
0.070 & 18.37 & 0.2800 \\
0.067 & 20.05 & 0.2600 \\
0.060 & 25.00 & 0.3200 \\
\hline
\end{tabular}

Topp, Roth, and the proposed calibration equation. The calibration curve had a fit with a good trend for the points related to measures with TDR. The range of water content estimated is from $0.22 \mathrm{~m}^{3} \mathrm{~m}^{-3}$ to $0.32 \mathrm{~m}^{3} \mathrm{~m}^{-3}$. The most similar values between the presented equations are from $0.25 \mathrm{~m}^{3} \mathrm{~m}^{-3}$ to $0.30 \mathrm{~m}^{3} \mathrm{~m}^{-3}$.

A polynomial form (similar to the Topp and Roth equations) for the proposed calibration equation was also established, being represented by:

$$
\begin{gathered}
\theta_{C E}\left(\epsilon_{r}\right)=0.1108+0.1367 \times 10^{-1} \epsilon_{r} \\
-0.2625 \times 10^{-3} \epsilon_{r}^{2}+0.3025 \times 10^{-5} \epsilon_{r}^{3} .
\end{gathered}
$$

The proposed calibration Eq. (14) was tested by estimating the water content in the trench at the $0.3 \mathrm{~m}$ depth (Fig. 7), being obtained the value $\theta_{C E}=0.2643 \mathrm{~m}^{3} \mathrm{~m}^{-3}$, which is close to the TDR measurement and to the values obtained with Topp and Roth equations.
The root mean square error (RMSE) of soil moisture estimates was determined by:

$$
s=\sqrt{\frac{\sum\left(\theta_{T D R}-\theta_{C E}\right)^{2}}{N}},
$$

in which $\theta_{T D R}$ is the value of estimated soil moisture via TDR methodology, $\theta_{C E}$ represents the soil water content values obtained by Eq. (14), and $N$ the number of points used in the regression. Substituting values of $\theta_{T D R}$ and $\theta_{C E}$ from Table 4 in Eq. (17), the RMSE for soil water content estimates obtained is around $0.0196 \mathrm{~m}^{3} \mathrm{~m}^{-3}$. In like fashion for the equations of Topp and Roth the respective RMSE are 0.061 and $0.041 \mathrm{~m}^{3} \mathrm{~m}^{-3}$.

The quality of the regression fit was checked using the coefficient of determination

$$
r^{2}=1-\frac{\sum\left(\theta_{T D R}-\theta_{C E}\right)^{2}}{\sum \theta_{T D R}^{2}-\frac{1}{N}\left(\sum \theta_{T} D R\right)^{2}} .
$$




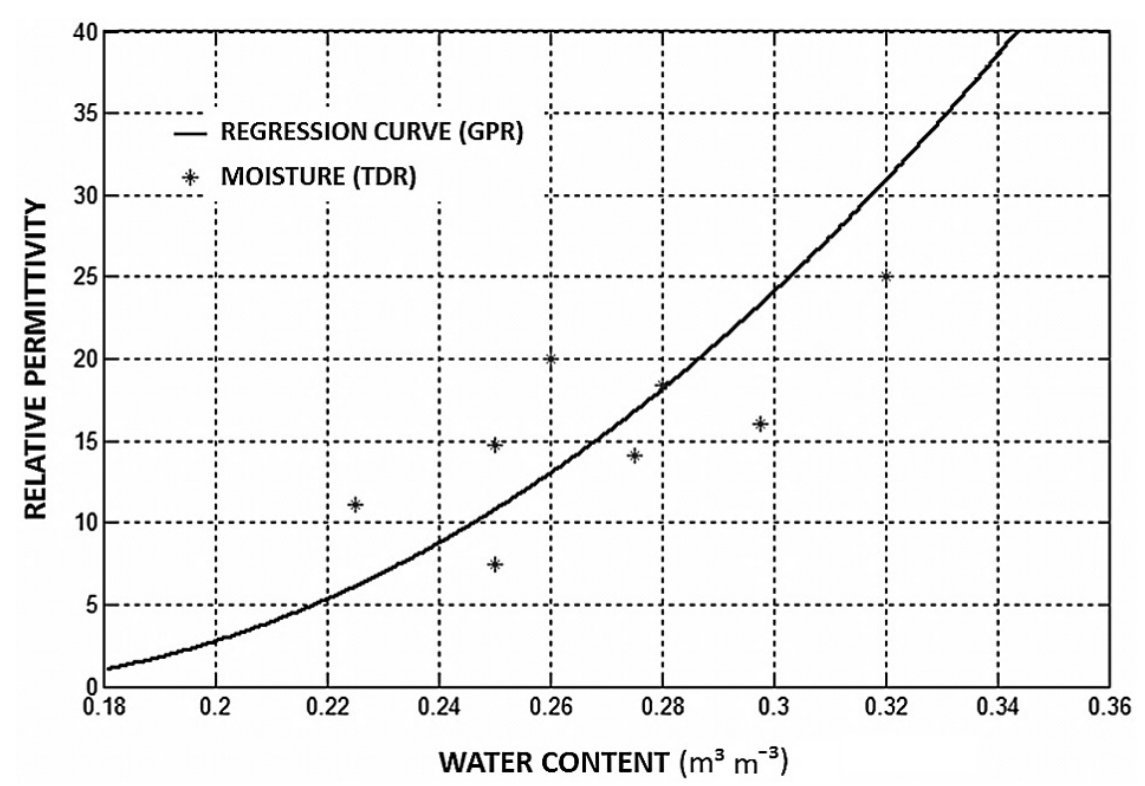

Figure 8 - GPR site-specific calibration curve fitted to the estimated soil water content.

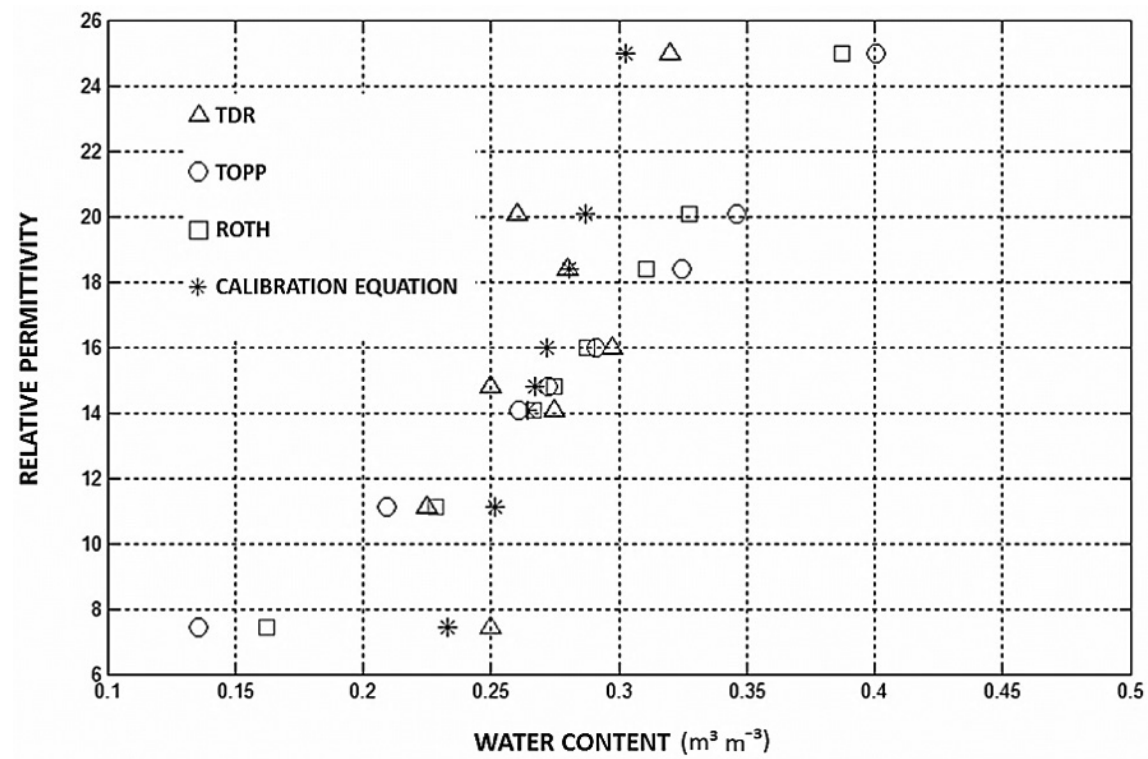

Figure 9 - Relative permittivity versus water content for TDR, Topp, Roth and the proposed GPR calibration equation.

Based on Equation (14), the coefficient of determination showed a value for $r^{2} \cong 0.514$.

\section{CONCLUSIONS AND RECOMMENDATIONS}

The study allowed for the establishment of a calibration equation for the specific type of soil that occurs in the investigated area at the UFPA test site. The estimated soil water content obtained with GPR using the Topp and Roth equations was similar to water content measured with TDR. Although not typically utilized in soil water content determination experiments under natural and uncontrolled conditions, the common-offset GPR antennas proved to be efficient because of the accurate moisture estimates obtained and the quickness and easiness for taking the measurements. However, the media must provide hyperbolic patterns in the GPR images in order to provide velocity determinations.

Determining soil water content through GPR wave velocity in common-offset configuration proved to be practical and rapid. Calibrate an equation for estimating soil water content using GPR 
showed to be possible from TDR information, since such information of water content be coherent (TDR already calibrated for the area or automatic calibration of the apparatus with good results).

More tests are needed since the study aimed to prompt action in the field. Soils with different moisture levels, use of direct methods and measures in rainy and dry periods are recommended for future research.

\section{ACKNOWLEDGEMENTS}

The first author is indebted to the members of the Postgraduate Course in Institute of Geophysics at UFPA and the National Council for Scientific and Technological Development (CNPq) for their help in research. The authors deeply thank the researchers from the Department of Meteorology at UFPA for their assistance in data collection.

\section{REFERENCES}

CAMPBELL SCIENTIFIC. 2011. Hydrosense Soil Water Measurement System - Instruction Manual. Available on: <http://www.campbellsci. com.au/documents/manuals/hydrosns.pdf $>$. Access on: November 1, 2011.

CAMPBELL SCIENTIFIC. 2012. CS650 and CS655 Soil Water Content Reflectometers. Available on: <http://s.campbellsci.com/documents/ us/product-brochures/b_s650.pdf>. Access on: August 5, 2012.

DAVIS JL \& ANNAN AP. 1989. Ground-penetrating radar for high resolution mapping of soil and rock stratigraphy. Geophys. Prospect., 37: 531-551.

DOBSON MC, ULABY RT, HALLIKAINEN MT \& EL-RAYES MA. 1985. Microwave Dielectric Behavior of Wet Soil - Part II. Dielectric Mixing Models. IEEE Trans. Geosci. Remote Sensing, GE-23: 35-46.

GROTE K, ANGER C, KELLY B, HUBBARD S \& RUBIN Y. 2010. Characterization of Soil Water Content Variability and Soil Texture using GPR Groundwave Techniques. J. Environ. Eng. Geophys., 15: 93-110.

HERKELRATH WN, HUMBURD SP \& MURPHY F. 1991. Automatic Real-Time Monitoring of Soil Moisture in a Remote Field Area with Time Domain Reflectometry. Water Resour. Res., 27: 857-864.

HUBBARD SS, PETERSON JE, MAJEREL, ZAWISLANSKIPT, WILLIAMS KH, ROBERTS J \& WOBBER F. 1997. Estimation of permeable pathways and water content using tomographic radar data. Leading Edge Explor., 16: 1623-1630.
HUISMAN JA, SPERL C, BOUTEN W \& VERSTRATEN JM. 2001. Soil water content measurements at different scales: accuracy of time domain reflectometry and ground penetrating radar. J. Hydrol., 254: 48-58.

HUISMAN JA, HUBBARD SS, REDMAN JD \& ANNAN AP. 2003. Measuring Soil Water Content with Ground Penetrating Radar: A Review. Vadose Zone J., 2: 476-491.

LEDIEU J, RIDDER PD, CLERCK PD \& DAUTREBANDE S. 1986. A Method of Measuring Soil Moisture by Time Domain Reflectometry. J. Hydrol., 88: 319-328.

LUNT IA, HUBBARD SS \& RUBIN Y. 2005. Soil moisture content estimation using ground-penetrating radar reflection data. J. Hydrol., 307: 254-269.

ROTH K, SCHULIN R, FLÜHLER H \& ATTINGER W. 1990. Calibration of time domain reflectometry for water content measurement using a composite dielectric approach. Water Resour. Res., 26: 2267-2273.

ROTH CH, MALICKI MA \& PLAGGE R. 1992. Empirical evaluation of the relationship between soil dielectric constant and volumetric water content as the basis for calibrating soil moisture measurements by TDR. Eur. J. Soil Sci., 43: 1-13.

RUBIN Y. 2003. Applied Stochastic Hydrogeology. Oxford, UK, Oxford University Press. 391 pp.

SANDMEIER KJ. 2011. ReflexW Version 6.0. Program for the processing of seismic, acoustic or electromagnetic reflection, refraction and transmission data.

SIDDIQUI SI \& DRNEVICH VP. 1995. Use of Time Domain Reflectometry for Determination of Water Content and Density of Soil. Report No.: FHWA/IN/JTRP-95/9, Join Transportation Research Program, Indiana Department of Transportation - Purdue University. 271 pp.

STEELMAN CM \& ENDRES AL. 2011. Comparison of Petrophysical Relationships for Soil Moisture Estimation using GPR Ground Waves. Vadose Zone J., 10: 270-285.

TOPP GC, DAVIS JL \& ANNAN AP. 1980. Electromagnetic of Soil Water Content: Measurements in Coaxial Transmission Lines. Water Resour. Res., 16: 574-582.

TORRES M. 2011. Geografia do Pará. Available on: < http://geomaurotorres.blogspot.com/2009/06/principais-tipos-de-solos-do-estado-do. html>. Access on: June 26, 2011.

WEILER KW, STEENHUIS TS, BOLL J \& KUNG K-JS. 1998. Comparison of Ground Penetrating Radar and Time-Domain Reflectometry as Soil Water Sensors. Soil Sci. Soc. Am. J., 62: 1237-1239. 


\section{NOTES ABOUT THE AUTHORS}

Marcelo Jorge Luz Mesquita graduated in Mathematics (2007) and M.Sc. in Geophysics (Electrical and Electromagnetic methods, 2012) from the Universidade Federal do Pará. Currently, is a Ph.D. student in Geophysics (Seismic Methods) at Universidade Federal do Pará.

José Gouvêa Luiz is bachelor in Geology from Universidade Federal do Pará, master in Geophysics from Universidade Federal da Bahia, and doctor in Geophysics from Universidade Federal do Pará. Currently, is retired professor of Universidade Federal do Pará, working in research. Research interest is applied geophysics to mineral and groundwater prospection, to environment contamination, and to Archaeology.

José de Paulo Rocha da Costa holds a doctorate in Agricultural Meteorology from the Universidade Federal de Viçosa (2008), a master degree in Meteorology from the Universidade Federal da Paraíba (1989), a specialization course in Tropical Meteorology from the Universidade Federal do Pará (1983) and bachelor in Meteorology from the Universidade Federal do Pará (1981). Currently, is Professor Associate III at the Universidade Federal do Pará. It operates in the areas of Micrometeorology with emphasis on meteorological instrumentation and agrometeorological modeling. 